\section{Billets d'humour et d'humeur}

\section{Pratique libérale de la dermatologie: en pleine évolution!}

Jusqu'ici sévèrement réglementée (ce qui veut dire inexistante), la publicité pour nos cabinets médicaux évolue...

Le Web a déjà modifié nos usages, soit discrètement, soit parfois d'une manière surprenante. Il est vrai que toutes les sociétés scientifiques suisses n'ont pas fait preuve de la sagesse de la SSDV, ni tous les médecins de la compréhension des dermatologues face à la déontologie et à la dignité médicale...

Les mœurs changent. Les officines de dermatologie esthétique se multiplient, leur publicité envahit les quotidiens à grands tirages, voire le métro de certaines cités lémaniques, parfois encore les Feuilles des Avis Officiels lors de leur faillite...

La politique change. Les politiciens croient avoir un long nez (on dit aussi un long tarin) en exigeant la fin de l'obligation de contracter... Fin qui serait peut-être une chance pour les praticiens écartés des aléas de la paperasserie et du Tarmed. Pourra-t-on encore les obliger à la garde et aux frais de l'organisation de celle-ci? Pourra-t-on encore leur interdire de faire de la publicité?
Le Conseiller Fédéral Couchepin, s'il a quelque logique, devrait alors laisser les médecins se faire libre concurrence comme il aime à le dire - c'est-à-dire leur laisser la liberté de promouvoir leurs activités et de faire de la publicité...

L'homme serait d'origine africaine selon les paléontologues...

Soit.

Alors retournons à nos sources et voyons quelle publicité pour nos activités.

Sans porter de jugement de valeur ou d'éthique, je vous soumets les annonces que publie un de nos collègues ivoiriens, astrologue et chercheur habile qui, lui, ne s'est pas muré dans sa tour d'ivoire...

Est-ce vers cela que nous allons nous orienter?

Pour le bien de nos patients...

Puisque notre collègue guérit visiblement plus de maladies que ne sait le faire le soussigné... et cela aussi bien les jours ouvrables que fériés!

Albert-Adrien Ramelet, Lausanne

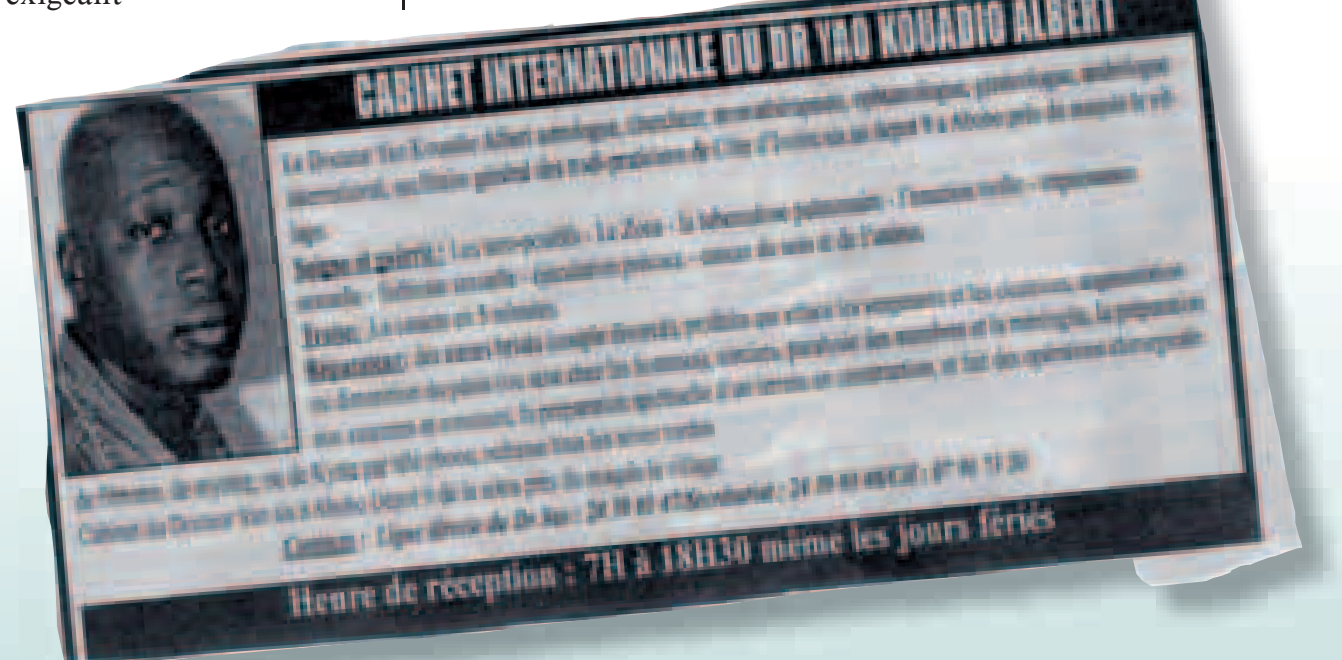

